\title{
Uma alternativa ao sujeito brasileiro do século XIX: representações de "A Jangada" de Júlio Verne
} An alternative to the 19th century brazilian subject: representations of "The Giant Raft" of Jules Verne http://dx.doi.org/10.5007/2178-4582.2016v50n1p26

Cássio Remus de Paula Universidade Estadual de Ponta Grossa, Ponta Grossa/PR, Brasil

\begin{abstract}
O presente artigo tem como objetivo apresentar as formas como Júlio Verne descreve as etnias branca, negra e indígena em sua obra "A Jangada". $\mathrm{O}$ romance, que se passa no norte brasileiro em 1852, expõe as diversas representações do imaginário do autor e da intelectualidade do século XIX. Referentes à construção do sujeito brasileiro, utilizam-se principalmente dois autores do mesmo século: Nina Rodrigues e Euclides da Cunha.

Palavras-chave: Júlio Verne, A Jangada, Representações, Nina Rodrigues, Euclides da Cunha.
\end{abstract}

The aim of this article is to present the ways how Jules Verne describes the white, black and indigenous ethnic groups in his novel "The Giant Raft". The events in the novel take place in 1852 in Brazil, evoking several imaginary representations of the author's and intellectuality of the nineteenthcentury. Considering the construction of the Brazilian subject, the nineteenth-century authors, Nina Rodrigues and Euclides da Cunha are principally used in the study

Keywords: Jules Verne; The Giant Raft: Representations, Nina Rodrigues, Euclides da Cunha.

\section{O cientificismo de Júlio Verne}

As obras de ficção científica de Júlio Verne (1828-1905) servem, atualmente, como documentos culturais que permitem problematizar as noções de ciência e de modernidade típicas dos séculos XIX e XX no Ocidente. Tais noções, advindas do otimismo científico e tecnológico, chegaram a ser transmitidas para os leitores em forma de arte, com atribulações mais vulgares e abertas ao senso comum, em contraste com as densas ideias presentes nos círculos científicos do mesmo período.

Juntamente com a noção positivista de progresso, havia a forma como o futuro próximo deveria ser pensado, conforme as inovações científicas e tecnológicas se tornavam cada vez mais presentes no cotidiano da humanidade. Na medicina, na física e na química, realizavam-se novas descobertas em ritmo quase constante. A literatura acompanhava esse otimismo de forma ousada, lançando ideias plausíveis de novidades científicas e tecnológicas para o futuro. É possível, por meio dos autores da ficção científica que produziram a partir do século XIX, compreender o imaginário de ciência que permeava os discursos intelectuais do ocidente. 
A ficção científica remete às obras inspiradas na ciência. Os primeiros exemplos de fictio - designação do latim que constata a prevalência literária - estão relacionados aos autores que espelharam diversos atributos imaginativos acerca da ciência no século XIX, tais como o francês Júlio Verne (18281905) e o inglês H. G. Wells (1886-1946). Esses autores são considerados os "pais da ficção científica", de acordo com a The Encyclopedia of Science Fiction (1995), organizada por John Clute e Peter Nicholls. Mas a concepção de que tais autores previram o futuro é errônea, dado que suas sugestões já estavam fervilhando na imaginação científica sobre o porvir. As viagens espaciais, por exemplo, não foram pensadas apenas a partir de Júlio Verne com "Da Terra à Lua" (1865) e "À Roda da Lua" (1870); tampouco pelas descobertas da astronomia que foram intensificadas a partir do século XVI. Desde as primeiras civilizações, sonhava-se com o não-possível, pois "recuando-se bastante no tempo, pode-se dizer que nasceu a ficção científica desde quando o homem começou a imaginar coisas que não existiam na sua época" (OTERO, 1987, p.23). Portanto, Verne não era um visionário, mas um intelectual atento à comunidade científica.

Uma das criações da ciência à qual Verne atentou, e a partir do que foi grandemente reconhecido, foi o submarino: cientistas bélicos da segunda metade do século XIX se voltavam em grande parte às pesquisas relacionadas a protótipos de uma máquina que pudesse submergir e servir de arma contra os navios. O primeiro modelo parecido com um submarino já havia sido fabricado em 1776 - o Turtle, ou "Tartaruga", que recebeu esse nome por lembrar a estrutura física do réptil enquanto nada. Com apenas $1,8 \times 1,3 \mathrm{~m}$ de dimensões, o seu único tripulante enxergava por uma pequena janela emersa, quase indetectável em meio às ondas. Com uma hélice de propulsão manual e duas brocas para perfurar navios - dando, em seguida, a possibilidade de instalação de explosivos nesse equipamento - o Turtle é possivelmente o primeiro submarino da história com fins militares. Sua primeira missão ocorreu em setembro de 1776, durante a Guerra da Independência dos Estados Unidos (1775-1783). Ao tentar sabotar o navio inglês HMS Eagle no rio Hudson, em Nova York, a broca do Turtle quebrou, mas o tripulante Ezra Lee conseguiu retornar a salvo. Após esse evento, a comunidade científica não desistiu do modelo, passando a aprimorá-lo.

No século XIX, por exemplo, foram lançados novos modelos, como o norte-americano Pioneer (1862) e o britânico Resurgam II (1879) (ABRIL COLEÇÕES, 2010). Se “Vinte Mil Léguas Submarinas” pôde ser lançado em 1870 é porque Verne estava atento. Ele não descobriu o submarino, mas fez uma leitura da máquina com suas próprias concepções, inserindo elementos de plausibilidade. De qualquer forma, o submarino que ele propunha, em 
questão de poucos anos, tornou-se realidade: a Alemanha, com a ascensão da Kriegsmarine (Marinha de Guerra), após a Primeira Guerra Mundial, produziu U-boats em massa - inclusive, muitos modelos elétricos, como os Tipo XXI e Tipo XXIII, cuja propulsão era similar à proposta de Verne em seu Nautilus de motor elétrico (PAULA, 2014, p.107-117).

Pode-se dizer portanto, baseado no exemplo acima, que as antecipações criadas pelos autores da ficção científica derivavam de sua atenção aos progressos vinculados à ciência, dado que o porvir pelas inovações tecnológicas já estava presente, de maneira ansiosa, nas concepções das comunidades científicas. Cabia aos autores da ficção científica, portanto, criar métodos convincentes de apropriações de tais inovações, baseados na expectativa e pensando em um futuro próximo.

\section{Noções da identidade brasileira a partir de Nina Rodrigues e Euclides da Cunha}

A partir da segunda metade do século XIX, o advento do progresso tecnológico e a tentativa quase frenética em se definir, com precisão, diversos atributos sociais e históricos - como uma herança de questões provenientes do Iluminismo - deram forma ao positivismo. A intelectualidade voltada ao positivismo buscava, assim, definir atributos que levassem o mundo ao progresso, pensando sempre em um futuro melhor do que a sua realidade presente. A partir dessa linha de pensamento, doutrinados aos moldes europeus que incitavam à construção da Civilização - uma nação baseada no progresso -, intelectuais como Francisco Varnhagen, Capistrano de Abreu e Sílvio Romero, por exemplo, procuraram estabelecer, pressupondo uma definição precisa, concepções sólidas relacionadas ao sujeito brasileiro.

Tal definição procurava apontar para as questões sociais atribuídas às diversas etnias presentes no país, sugerindo, inclusive, métodos que levassem à sua purificação. Isso significa que procuravam definir, em um primeiro momento, conceitos baseados no evolucionismo darwinista. Dessa forma, viriam a identificar "problemas" na sociedade brasileira, em grande parte provenientes dos negros e indígenas, para, em seguida, apontar diversas sugestões de como moldá-los, ou até mesmo extingui-los por meio de processos de branqueamento - sempre em prol da Civilização. Tais "problemas" estariam vinculados às supostas tendências selvagens dessas etnias, consideradas uma afronta ao futuro. Conforme aponta Renato Ortiz (2013, p.615), "diante da heterogeneidade de raças desiguais, o futuro repousaria na supressão lenta e gradual das deficiências hereditárias do brasileiro". Os intelectuais positivistas acerca da identidade brasileira, portanto, perceberam que o processo 
de branqueamento ocorreria de forma lenta, de tal modo que seria necessário um constante processo de mestiçagem para que as "raças inferiores" fossem finalmente extintas.

Procuraram-se, a partir de então, características que apontassem os defeitos vinculados a cada etnia. $\mathrm{O}$ resultado foi, em grande parte, frustrante: Raimundo Nina Rodrigues (1862 - 1906) e Euclides da Cunha (1866 - 1909), dentre o rol de intelectuais preocupados com o progresso social no Brasil, concluíram que a identidade brasileira era de fato decadente, dado que os mestiços e demais povos não-caucasianos eram os que compunham a sua maioria; se algum progresso que levasse à Civilização no Brasil fosse possível, a consistência dessa identidade parecia uma afronta extremamente sólida.

Inseridos em um contexto positivista de obtenção precisa de resultados, cientistas e intelectuais preocupados com temas psicossociais, partilhavam de uma visão semelhante no que tange à construção conclusiva de uma identidade do sujeito brasileiro. Para que se possa compreender a síntese, realizada no presente trabalho, sobre a proximidade do pensamento de tais autores com a obra $A$ Jangada, de Júlio Verne, é de grande importância que se atente a duas obras em específico. A primeira é Os Africanos no Brasil, de Nina Rodrigues, na qual o médico expôs seus estudos acerca da definição biológica e racial vinculada aos afro-brasileiros a partir de investigações antropológicas. Embora tenha sido escrita durante a década de 1900, a obra viria a ser publicada apenas em 1932, quando do falecimento do autor. A segunda obra em questão é Os Sertões, de Euclides da Cunha, na qual o autor procurou apresentar uma definição do sujeito brasileiro a partir das concepções biológicas assimiladas ao homem do norte e do nordeste do país, baseando-se no advento da Guerra de Canudos (1896-1897). O livro, lançado em 1902, repercutiu positivamente dentre seus pares, recebendo elogios de Araripe Júnior, José Veríssimo e Sílvio Romero (DANTAS, 1967).

Em ambas as obras são inseridas noções do evolucionismo biológico, social e psicológico desenvolvidas por Charles Darwin (1809 - 1882), que ignorou os fatores históricos ao documentar a separação racial do ser humano, de forma que o selvagem - o negro, o indígena ou indiano - seria suscetível à decadência mental e emocional em decorrência das influências do meio onde vive. Herbert Spencer (1820 - 1903), posteriormente, classificou o selvagem como uma espécie secundária, afirmando que nem toda evolução biológica era positiva e dizia respeito ao progresso (CHAVES, 2003). Fundamentadas nessas teorias raciais, doravante, tais acepções foram atribuídas ao sujeito brasileiro pelos intelectuais do século XIX. Nina Rodrigues (2010 [1932]) discutia o sujeito africano no Brasil como um problema, mas propenso à extinção, conforme passava pelo processo de mestiçagem- atributo até então 
associado à decadência da natureza. Mas Nina não discorria suas teorias sem certo sentimento de pena, pois lembrava aos leitores que os negros sofriam "todas as violências por parte dos senhores de escravos, [...] de feitores tão brutais e cruéis quanto ignorantes" (RODRIGUES, 2010, p.264). Da mesma forma, Euclides da Cunha procurou definir o mestiço de maneira depreciativa: este perdia tanto os atributos físicos do negro, quanto os dos intelectuais brancos. Ou seja, os mestiços sofriam das deficiências de todas as características positivas de raças, tanto vinculadas ao branco quanto ao negro, as quais moldaram-se por milênios em seus respectivos habitats sob intermédio do progresso natural (CUNHA, 2007).

Tais teorias, criadas sob a urgência em se definir as diversas concepções que constituiriam o sujeito brasileiro, podem ser associadas às noções que Júlio Verne em seu romance "A Jangada" - no qual apresentava sugestões sobre uma alternativa à identidade do sujeito brasileiro - embora tal romance tenha sido derivado do imaginário de um intelectual francês em relação ao Brasil.

\section{Sobre "A Jangada"}

A obra de Júlio Verne intitulada La Jangada, de 1881 - traduzida como "A Jangada" para o português - apresenta o contexto da rica família de João Garral que se aventura pelo norte brasileiro no ano de 1852, descendo o Rio Amazonas a partir de Iquitos, aldeia peruana, sobre uma refinada e gigantesca jangada. Sob o pretexto de casar sua filha, Minha, com o amigo de seu filho Bento, Manuel, na cidade de Belém, o verdadeiro intuito de Garral é investigar sobre uma falsa acusação de roubo que o condenara à morte.

A trajetória de viagem descrita por Verne é composta de ricas informações sobre a fauna e flora da floresta amazônica, sem excluir as diversas composições étnicas presentes em seu contexto: o branco, o negro e o indígena. Ainda em um recorte temporal inserido nas recentes políticas escravistas do Ocidente, Verne ,por sua vez, excluiu da personalidade do protagonista - Garral - os sentimentos e práticas dos escravocratas, por mais que este fosse um rico dono de fazendas em terras amazonenses. E, mesmo com uma detalhada abordagem sobre a floresta, seja em seus atributos naturais ou contextos sociais, o romancista nunca chegou a pisar em território brasileiro (RIAUDEL, 1992, p.66). Ainda que haja toda uma elaboração contextual extremamente amistosa referente às relações dos diversos personagens - inclusive em decorrência do fato de Júlio Verne ser um declarado abolicionista (PELLEGRINO, 2009) não se pode deixar de notar a presença das diversas representações associadas às três etnias no decorrer da obra. 


\section{Atribulações do homem branco}

Um dos primeiros personagens a serem enfatizados por Verne em sua obra é João Dacosta, brasileiro pobre e solitário que trabalhava em Minas Gerais na extração de metais durante o Segundo Reinado (1840-1889). Injustamente acusado de roubo e assassinato de guardas reais, criou o pseudônimo de João Garral e fugiu pelas fronteiras peruanas. Na aldeia de Iquitos, foi acolhido por Magalhães, um gentil português proprietário de uma feitoria com terras e exportador de madeira que, no dizer de Verne, era ignorante em relação à administração de seus negócios. Sob auxílio de Garral, a família de Magalhães ascendeu economicamente e, como agradecimento por parte do proprietário, Garral veio a receber metade dos lucros da produção da fazenda. Em um acidente, Magalhães faleceu, não antes de casar sua filha Yaquita com o expatriado. João tornou-se o subsequente proprietário de seus negócios e terras.

É possível extrair concepções a partir da relação entre a personalidade de João Garral e o fato de ser branco. Num momento em que a mestiçagem é evidente no Brasil, numerosa dentre os trabalhadores braçais na extração de metais, é difícil que o personagem seja conduzido a uma posição de elite por mera coincidência. Embora miserável e exausto, tanto pela fadiga quanto pela fome, Magalhães se deparara com um homem de "expressão nobre e altiva". Não obstante, Garral "era instruído e inteligente. Tinha [...] indício infalível do homem sincero, cujo modo de pensar é recto [sic] e são" (VERNE, 2003 [1881], p.25).

Ora, para Nina Rodrigues (2010), os brancos seriam biologicamente superiores, implicando uma série de vantagens sobre as demais raças, dentre as quais o fato de serem excelentes administradores -atributo que permitiu a ascensão social de João Garral, apesar de sua origem miserável. O fato de o personagem ser branco o associa à noção de civilidade, constituindo-se na personificação de uma "raça forte", tal como Euclides da Cunha (2007) incita a concluir em relação ao homem branco.

Mas João não é o único personagem a ser vinculado aos conceitos de civilidade. O vilão da trama, Torres, é também um homem branco. No intuito de enfatizar seus traços de maldade, Júlio Verne coloca em sua história um passado provocativo: Torres havia sido um capitão do mato, ou seja, caçava escravos negros que fugiam de seus senhores. E, tal como João Garral, era miserável, mas curiosamente dotado de formalidades, como um sir aos modos europeus do século XIX. E, às maneiras da Civilização, o filho de João - Bento - também servia de exemplo em relação à cortesia e às formalidades: 
tinha doze anos foi mandado para Belém, capital do Pará, onde, sob supervisão de excelentes professores, recebeu a instrução que devia torná-lo mais tarde um homem distinto. Aprendeu de tudo, letras, ciências e artes. [...] Não pensava, como tanta gente, que a riqueza dispensa o trabalho, mas sim que ninguém deve subtrair-se a esta obrigação se quiser merecer o nome de homem (VERNE, 2010, p.28).

Ao afirmar que Bento estivera "sob supervisão de excelentes professores", Verne aludiu à herança hierárquica das etnias, derivadas do pensamento intelectual do século XIX. Em sintonia com a intelectualidade europeia, cabia ao personagem um atributo superior de mentalidade, ao passo que, de forma muito defendida dentre os intelectuais do ocidente, era cabível a ideia de que o homem branco fosse propenso à superioridade, dado que "caberia aos brancos o topo da hierarquia humana, postura que, esta sim, estava em perfeita sintonia com alguns dos prestigiosos intelectuais europeus da época" (SCHNEIDER, 2011, p.169). Esta característica deveria ser colocada em prática pela humanidade a ponto de extinguir as etnias inferiores. No dizer de Euclides da Cunha, se "a raça forte não destrói a fraca pelas armas, esmaga-a pela civilização" (2007, p.144), ou seja, a tendência da "raça forte" era sobreviver acima das demais, tais como atribuíra Darwin em relação ao desaparecimento de espécies ditas inferiores.

Muito embora essa concepção de superioridade do homem branco fosse aceita, Euclides admitia haver uma hierarquia dentro da própria etnia caucasiana. Pressupondo tal perspectiva, pode-se atribuir ao português Magalhães, antigo dono de Iquitos, a ignorância nos quesitos administrativos. Compensando sua inaptidão para o comércio, Magalhães era "hospitaleiro como todos os portugueses da velha raça" (VERNE, 2003, p.25). Portanto, embora o personagem possuísse uma boa índole, era desprovido da inteligência necessária para que administrasse bem sua fazenda. $\mathrm{O}$ argumento de Euclides é o de que sua improdutividade seria decorrência do meio onde vive. Se para José Veríssimo (RODRIGUES, 1894, p.134), o português seria de uma raça "civilizada, superior, porém mal-educada e representada talvez pelo que tinha de pior", Euclides explica que, das florestas amazônicas que abrangem grande porção do norte latino até o Mato Grosso, o homem sofre um processo de decadência intelectual devido ao extenuante calor úmido do ambiente.

Decorrem, desse clima, deficiências na energia do indivíduo, tornando-o mais emotivo que racional. Seu sangue empobrece como se fosse atingido por um problema patológico; a aclimação degenere o sujeito português aí inserido, ao passo que em poucas gerações, tem-se um produto de atributos físicos e morais inferiores a de seus antecessores (CUNHA, 2007). 
Dessa forma, percebe-se pela escrita de Verne, a construção de representações que tentam caracterizar o padrão social e psicológico de seus vários personagens. Dentre tantos, porém, é perceptível que os personagens de etnia branca são providos de inteligência e inclinam-se ao sucesso econômico, através de dons administrativos ou simplesmente a partir de exercícios ilegais - excluindo-se Magalhães, embora este seja, ainda, representado como membro de uma classe social mais elevada que a maioria, mesmo sem ter convivido nos ambientes propícios ao desenvolvimento da intelectualidade que, nos dizeres de Euclides da Cunha, durante toda sua obra, chamava-se Civilização.

\section{Os negros de Iquitos}

Ambientado em uma época em que a escravidão ainda permeava o cotidiano dos senhores da América, o romance de Verne exclui, por sua vez, os hábitos brutais da relação entre o homem branco e o escravo negro, pelo menos na propriedade de João Garral. Há uma referência, em particular, no último parágrafo do capítulo III que explica o ambiente de repulsa à escravidão presente na fazenda de Iquitos. Nela, existem serviçais de "duas espécies": aproximadamente cem índios para o "tamanho da fazenda" e duzentos "pretos que ainda não eram livres, mas cujos filhos não nasciam já escravos", de forma que "na fazenda de Iquitos nunca houve desses tristes exemplos de crueldade que são tão frequentes nas plantações estrangeiras" (VERNE, 2003, p. 32). Dentro do território brasileiro, porém, Verne narra que os escravos de Benguela e do Congo foram tratados com mais amenidade que nos demais países, muito embora a fazenda se localizasse no Peru.

Não existem muitas referências à raça negra dentro de $A$ Jangada, pois o autor prefere atentar às representações dos nativos amazônicos. Por sua vez, Verne apresenta ao leitor duas personagens que merecem atenção: Cíbele e Lina. Cíbele, "livre por vontade de seu amo, escrava pela afeição que the consagrava e a toda a família", é uma "velha preta" de sessenta anos (Ibid., p.32). Temerosa com o tráfico de escravos, fixou-se em Iquitos de forma que nunca conheceu lugares além da fazenda desde o momento em que fora acolhida por Magalhães. Apesar do receio com o mundo afora, a personagem é descrita afavelmente.

Para Nina Rodrigues (2010), não sem sentimento de pena, por mais que um negro esteja inserido em uma comunidade branca, haverá ele de se portar como uma criatura deficiente, alheia à Civilização. Mais exatamente, para ele, de acordo com Neves: 
[...] as raças inferiores se caracterizam pelas ações impulsivas e violentas. Os indivíduos que as constituíam não seriam capazes de evoluir porque não compartilhavam dos mesmos "motivos psíquicos de ordem moral" das raças superiores (NEVES, 2008, p.249).

Muito embora o imaginário de grande parte da intelectualidade concordasse com tais concepções, Júlio Verne parecia abster-se delas. Cíbele chegou a se casar em Iquitos, embora tenha se tornado viúva e tivesse perdido seu filho. Fiel a Magalhães, o acompanhou em seu leito de morte, mas continuou a servir a fazenda administrada por Garral. Gozava de liberdade e confortos, tal como os demais membros da família de João - embora existissem outras centenas de serviçais negros. A esse respeito, Octavio Ianni (1962) afirma que a inserção do negro no ambiente dos brancos - tal como é o caso de Cíbele em relação à família Garral - pode ser vista como uma redenção pelos anos de escravidão, permitindo assim que usufruam dos mesmos atributos que o homem branco dispõe.

Da mesma forma afável é apresentada Lina, ama de Minha, a qual Verne constantemente chama de "mulatinha".

\footnotetext{
Era uma gentilíssima rapariga, um pouco caprichosa, dessas que tomam às vezes demasiada confiança, mas às quais tudo se perdoa por causa da enorme dedicação que têm com as amas. E como era viva, buliçosa e meiga, deixavam-lhe fazer tudo o que lhe vinha à cabeça (VERNE, 2003, p.32).
}

Não há o que deprecie a mestiçagem de Lina no decorrer do romance, mas tais descrições de Verne não eram partilhadas pela maioria dos intelectuais do século XIX, que se posicionavam de maneira oposta. Para Silvio Romero (1888, p. 2), por exemplo, "todo brasileiro é um mestiço, quando não no sangue, nas ideias." É bem verdade que Verne (2003, p.62) lembra ao leitor que "uma ideia da Lina não pode ser senão doida", mas é com imensa dificuldade que se pode associar tal afirmação com as de Sílvio Romero ou as de Nina Rodrigues. Tal associação pode ser até mesmo indevida. As características de Lina parecem condizer com a personificação da informalidade, da aventura e do desleixo de forma saudável, de forma que suas ações parecem sempre trazer bons resultados.

Euclides parece não concordar com a ideia de que mestiços possam usufruir de qualidades. Ele afirma que eles seriam produto, sem atributos positivos, que a natureza selecionara com dificuldade no decorrer dos milhões de anos. De repente, a mistura os tornava deficientes, perdendo tanto as qualidades do intelecto do branco quanto as da virilidade do negro (CUNHA 2007). 
Portanto, tal afirmação sugere que, para Euclides da Cunha, o mestiço seria um produto ainda inferior da união entre o branco e o negro. Já Júlio Verne não associa seus personagens a atributos negativos; ao contrário, eles são essenciais para o desenvolvimento da trama, como é o caso de Lina, que possuía diversas peculiaridades positivas.

\section{Os indígenas amazônicos}

Ao contrário da presença dos negros, em A Jangada, Verne não insere personagens indígenas no romance, mas coloca-os como parte do cenário amazônico. Aos arredores de Iquitos, o autor afirma que os nativos andavam quase nus "e certamente há-de decorrer ainda muito tempo antes que a moda modifique o costume primitivo", apesar de que os espanhóis e mestiços "desprezavam [...] seus concidadãos indígenas", devido às suas raras vestimentas (VERNE, 2003, p.24).

Além de apontar seus atributos estéticos, Verne esclarece também que os indígenas são poderosos trabalhadores, principais construtores da colossal jangada:

\begin{abstract}
Trabalho fácil, em verdade! Sob a direção de João Garral, iam os índios serviçais da fazenda desenvolver sua habilidade, que é incomparável. Para tudo são estes indígenas jeitosíssimos operários, ou seja, construção de casas ou de barcos. Não têm senão um machado e uma serra, trabalham em madeiras [...] sem auxílio de máquina, pois têm como auxiliares a paciência e uma prodigiosa habilidade (VERNE, 2003, p.70).
\end{abstract}

Porquanto Garral fosse associado ao engenheiro da obra, os indígenas teriam sido os responsáveis pelo trabalho braçal. Diferentemente dos mestiços, os "selvagens", segundo Euclides da Cunha (2007, p.141), possuíam energia física e, por isso, conseguiam realizar suas tarefas com relativa facilidade. No contexto temporal da obra de Verne, porém, diferente dos negros, os indígenas são trabalhadores livres. Construída a jangada, os aposentos dos índios eram choças sem parede, pois, "acostumados a viver ao ar livre, não teriam podido habituar-se àquela espécie de prisão de cubata que convinha mais à vida dos pretos" (VERNE, 2003, p.80).

Nina Rodrigues, na obra "As raças humanas e a responsabilidade penal no Brasil" (1894), categorizou o índio como uma raça tão pura quanto a do negro, chamando-os de "raça vermelha" Por sua vez, concordava com Silvio Romero, para quem o negro seria mais adaptável à Civilização: 
O negro [...] é adaptável ao meio americano; é suscetível de aprender; não tem as desconfianças do índio; pode viver ao lado do branco, aliar-se a ele. Temos hoje muitos pretos que sabem ler e escrever: alguns formados em direito, em medicina, ou engenharia; alguns comerciantes e ricaços; outros jornalistas e oradores. Ao negro devemos muito mais do que ao índio; ele entra em larga parte em todas as manifestações de nossa atividade. Cruzou muito mais com o branco (ROMERO, 1888, p.28).

Dessa forma, não é difícil imaginar a aversão que os intelectuais do século XIX, tomados pelo viés de Romero, tinham a respeito dos costumes dos ameríndios latinos. Júlio Verne, por sua vez, não se limita a citá-los e descrevê-los, enfatizando a presença quase constante de seus diversos povos. Conforme a família de Garral desce o Rio Amazonas até Belém, por exemplo, Verne (2003, p.91-97) descreve características de várias tribos: os Marahuas, de longos cabelos e uma espécie de leque de espinhos que lhes adorna a boca, cujas mulheres da tribo fumavam charutos; os Ticunas, "zebreados de desenhos na face" e vestidos com tiras de algodão; os Cotos, de narizes trespassados por varinhas de palmeira, os quais "diz alguém que [...] sejam antropófagos", dentre outros.

Em contraste com Nina Rodrigues (1894) que afirma ser o índio imutável mesmo se escravizado, pois não se adapta à civilidade e que será sempre, graças à sua natureza, inevitavelmente selvagem, Júlio Verne não os representa dessa forma; tampouco os coloca como seres submissos: às margens das ilhas Iatio e Cochiquinas, "andavam armados de flechas e de sarabatanas [sic], mas não fizeram uso delas" (VERNE, 2003, p.93). O autor alude até mesmo à História do Brasil: "Qual é teu direito na tua tribo? - perguntava Montaigne a um índio que encontrou no Havre. É o direito de ser o primeiro a marchar para a guerra! - respondeu o índio (Ibid., p.106).

Posterior ao diálogo, Verne escreve que "a guerra, como se sabe, foi durante muito tempo o mais seguro e rápido veículo de civilização" (2003, p.107). A defesa moral que o autor faz do índio não se limita à sua força, mas faz menção ao seu fenótipo. $O$ barbeiro Fragoso, que atende às comunidades indígenas, explica que as índias não precisam se pentear todos os dias, como fazem as "mulheres elegantes" das cidades brasileiras. "Quando estão penteadas, estão-no para um ano", e por isso visita as aldeias a cada demorado espaço de tempo. Mas Fragoso não as visita sem a condição de se basear nas modernas modas de Belém ou Rio de Janeiro (Ibid., p.110-113).

Pode-se dizer que o intuito do barbeiro é inserir, mesmo que inconscientemente, o indígena na sociedade branca. Ora, por muito tempo a inserção do índio, tanto quanto a do negro, foi defendida a fim de incentivar a miscigena- 
ção. Essa prática viria, consequentemente, a extinguir as raças inferiores já que, baseando-se nos conceitos darwinistas, a branca seria a mais forte. Para Euclides da Cunha (2007, p.123), "sem ideia [sic] alguma preconcebida, pode-se afirmar que a extinção do indígena, no norte, proveio, segundo o pensar de Varnhagen, mais em virtude de cruzamentos sucessivos que de verdadeiro extermínio". De acordo com Oliveira (2002), ainda que otimista em relação ao branqueamento do brasileiro, Euclides afirmava que os selvagens eram uma afronta à Civilização; ou seja, os indígenas seriam um verdadeiro obstáculo ao progresso. Concepção semelhante à de Nina Rodrigues para quem o índio, em mistura com o branco - mais especificamente o português - resultava numa criatura decadente, sem ambições e luxos, entregues à preguiça e à morosidade (RODRIGUES, [1894]). Pode-se dizer, portanto, que na visão desses autores o indígena era mais hostil ao progresso que o próprio negro, embora ambos fossem de "raças puras". Atribuía-se ao nativos brasileiros uma concepção natural de rebeldia inconsciente - rebeldia esta que sabotava os moldes civilizatórios e a Civilização em si, tornando-se um empecilho que impedia o homem branco de consolidar um país refletido nos padrões europeus de progresso.

\section{Considerações finais}

Num momento em que os intelectuais franceses expunham suas concepções sobre tantos fatores históricos, Júlio Verne não deixava de realizar críticas sobre diversas identidades ao redor do mundo, inseridas sutilmente em seus romances. Muito embora inserisse diversas personificações acerca das etnias, o autor parecia se basear nos fatores próximos à realidade, como por exemplo, as posições sociais relacionadas à cor - com exceção, talvez, de João Garral. E, embora Verne fosse um abolicionista, seria estranho aos olhares da época, principalmente proveniente de seus pares, que apresentasse uma história cujo protagonista fosse negro: não estavam acostumados com tal perspectiva. Além disso, o público leitor não incluía o negro, já que este, de maneira genérica, estava ainda inserido em uma sociedade pós-escravista e genericamente analfabeta. É nesse sentido que se pode entender as obras de Júlio Verne como "a escrita de seu tempo", permeada no imaginário não apenas do autor, mas também de vários intelectuais e seus leitores.

Para que se entendam tais concepções abolicionistas presentes na literatura, é essencial compará-la com as obras daqueles que enxergam a inserção das etnias "inferiores" na sociedade como um obstáculo ao progresso. Diferentes autores, convencidos de que haveria uma espécie de fórmula que identificasse com precisão as diversas etnias presentes no Brasil e no mundo, imersos na concepção positivista, procuravam legitimar teorias que, ao nosso olhar 
contemporâneo, podem parecer absurdas. Mas, em um passado relativamente próximo, tais concepções foram adotadas por muitos intelectuais que sentiram-se obrigados a transmitir suas teorias para os leitores de suas obras.

O "pai da ficção científica", muito embora tenha obtido renome por suas extraordinárias e mirabolantes previsões, estava atento às demais concepções de mundo formadas por intelectuais sociais e antropólogos. E é devido a tal atenção que podemos analisar, atualmente, as diversas representações da sociedade norte-brasileira, então adotadas pela intelectualidade novecentista da França e, provavelmente de maneira similar, da Europa.

\section{Referências}

ABRIL COLEÇÕES (Org.). Submarinos: 1776-1940. São Paulo: Ed.Abril, 2010. 178 p. (Coleção Armas de Guerra, 17)

BOMBARDI, Fernanda Aires; CHAMBOULEYRON, Rafael. Descimentos privados de índios naAmazônia colonial(séculos XVII XVIII). In: Varia História:Belo Horizonte, v.27, n.46, 2001. Disponível em: <http://www.scielo.br/scielo.php?pid=S0104-87752011000200011\&script=sci arttext> Acesso em: 9 dez. 2014.

CHAVES, Evenice Santos. Nina Rodrigues: Sua interpretação do evolucionismo social e da psicologia das massas nos primórdios da psicologia social brasileira. Psicologia em Estudo, Maringá, v.8, n.2, p.29-37, 2003.

CUNHA, Euclides da. Os Sertões: Campanha de Canudos. São Paulo: Editora Martin Claret Ltda., 2007. 648p.

DANTAS, Paulo. Antologia Euclidiana. São Paulo: Pioneira, 1967. 255p.

IANNI, Octavio. As metamorfoses do escravo: Apogeu e crise da escravatura no Brasil Meridional. São Paulo: Difusão Europeia do Livro, 1962. 268p.

NEVES, Marcia das. A concepção de raça humana em Raimundo Nina Rodrigues. Filosofia e História da Biologia, v.3, p. 241-261, 2008.

OLIVEIRA, Ricardo de. Euclides da Cunha, Os Sertões e a invenção de um Brasil profundo. Rev. Bras. Hist., São Paulo, v. 22, n. 44, p. 511-537, 2002 . Disponível em: <http://www. scielo.br/scielo.php?script=sci_arttext\&pid=S0102-01882002000200012\&lng=pt\&nrm=iso $>$. Acesso em: 10 dez. 2014.

ORTIZ, Renato. Imagens do Brasil. Revista Sociedade e Estado. Brasília, v.28, n.3, p.609-633, set./dez. 2013. Disponível em: <http://www.scielo.br/pdf/se/v28n3/a08v28n3.pdf> Acesso em: 23 nov. 2015.

PAULA, Cássio Remus de. Corrida submarina: a ascensão tecnológica dos submarinos da Kriegsmarine de 1919 a 1945. Revista Marítima Brasileira. Rio de Janeiro, v.134, n.10/12, p.107117, 2014. 
PELLEGRINO, Gabriela. Selva acolhedora. Revista de História.com.br, 06/05/2009. Disponível em: <http://www.revistadehistoria.com.br/secao/leituras/selva-acolhedora $>$ Acesso em: 2 dez. 2014.

RIAUDEL, Michel. O rio palimpsesto: o Amazonas de Júlio Verne, das fontes à ficção. Revista

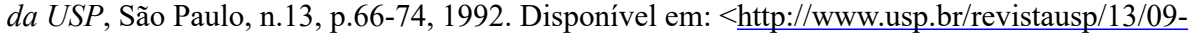
michel.pdf> Acesso em: 2 dez. 2014.

ROMERO, Silvio. História da Literatura Brasileira. Rio de Janeiro: H. Garnier, 1888, v.1. Disponível em: <http://www.santoandre.sp.gov.br/pesquisa/ebooks/344495.pdf> Acesso em: 17 mar. 2016.

RODRIGUES, Raymundo Nina. Os africanos no Brasil [online]. Rio de Janeiro: Centro Edelstein de Pesquisas Sociais, 2010. 303 p. Disponível em: <http://static.scielo.org/scielobooks/ mmtct/pdf/rodrigues-9788579820106.pdf > Acesso em: 02 mai. 2016.

. As raças humanas e a responsabilidade penal no Brasil. Rio de Janeiro: Editora Gua$\overline{\text { nabara }}$ - Waissman Koogan LTDA, s/d. [1 ${ }^{\text {a }}$. ed. 1894]. Disponível em: < $\underline{\text { http://www.cairu.br/ }}$ biblioteca/arquivos/Direito/As_racas_humanas_responsabilidade_penal_Brasil.pdf $>$ Acesso em: 4 dez. 2014.

SCHNEIDER, Alberto Luiz. O Brasil de Silvio Romero: Uma leitura da população brasileira no final do século XIX. Projeto História, São Paulo: PUC-SP, n.42, p.163-183, 2011. Disponível em: <http://revistas.pucsp.br/index.php/revph/article/view/7982/5852> Acesso em: 02 mai.2016.

VERNE, Júlio. A Jangada. Barcelona: RBA, 2003.

Submissão em: 06/01/2015

Revisão em: 17/03/2016

Aceite em: 06/04/2016

Cássio Remus de Paula é bacharel e mestrando em História pela Universidade Estadual de Ponta Grossa. Endereço para correspondência: R. Maria Auxiliadora, 125. Neves. CEP 84020-340. E-mail: remus_stuka@hotmail.com 